\title{
Psychotherapy Supervision: The Attitudes of General Psychiatrists
}

\author{
Stuart Leberman and John Cobb, Department of Psychiatry, St George's Hospital Medical School
}

Do consultant psychiatrists believe that psychotherapy supervision should be an integral part of the training of the junior doctors? If they do, when, where, for how long and by whom do they feel that supervision should be done? In the South West Thames Region we circulated a questionnaire to all general psychiatric consultants in an attempt to answer these questions. We report on some results of our survey and raise important immediate issues which would seem a subject for debate. The major issue is the debate about specialist psychotherapists versus psychodynamic psychiatrists. Although the College seems to favour strongly that psychotherapy teaching for general psychiatrists should be done by psychotherapy specialists, the 'consumer' appears to have a conflicting view, at least in our region.

Our questionnaire contained three parts:

(1) The Supervision Questionnaire (15 items). We defined psychotherapy supervision as: "the ongoing assessment and guidance of a trainee meeting on a regular basis to discuss the psychological management of patients and their familiarity with psychological treatments. Psychological treatments include the full range of psychotherapies (individual, group, family, behavioural and analytic).'

Thirteen statements about psychotherapy supervision were answered on a 5-point scale: strongly agree; agree; neutral; disagree; and strongly disagree. Two questions ask how many hours supervision should be given per week and what year should supervision start in training.

(2) The $A T Q I$ is an attitude to treatment scale (Caine and Smail, 1969). Low scores indicate a 'psychotherapeutic' orientation, high scores an 'organic' orientation (Pallis and Stoffelmeyer, 1973). Selection of the highest and lowest quartiles allowed us to define groups of 'organically-minded' and 'psychotherapeutically-minded' consultants, in order to compare their responses.

(3) The Actual Practice of Supervision asked about the actual supervision time of junior doctors, what sort of supervision was provided, who did the supervision and whether the consultant wished to attend a supervision seminar. General comments were also invited.

\section{Results} 74).

Sixty-one per cent returned the questionnaire (45 out of

\section{Supervision Questionnaire}

Eighty-nine per cent (40) of consultants indicated that junior doctors need psychotherapy supervision as an integral part of their training. Ninety-three per cent (42) believed that psychotherapy supervision should be obtained within the
NHS and 80 per cent (30) that it should occur in the junior doctor's hospital. All respondents agreed that supervision should be for at least two hours a week and 89 per cent thought that three hours were necessary. Eighty-seven per cent felt that supervision should begin in the first two years of training. Eighty-two per cent felt that supervision should be done by consultant psychiatrists with a special interest in psychotherapy. Sixty-nine per cent felt that supervision was best done individually. No psychiatrist indicated that psychoanalysts would be the only suitable supervisors.

\section{The ATQI and Actual Practices Questionnaires}

These revealed that 'organically-minded' psychiatrists were significantly more likely to favour supervision of junior doctors by general psychiatrists than psychotherapeuticallyminded consultants.

Only 29 (64 per cent) out of the 45 respondents gave details of the hours of supervision received in their respective hospitals by junior doctors. Fifty-eight doctors in the subconsultant grades received on average 1.26 hours per week. Most of this was discussion (83 per cent) in either group supervision (62 per cent) and/or individual supervision (59 per cent). Only 28 per cent of these juniors were exposed to the use of audio- or video-tape feedback; 17 per cent were able to use a one-way screen during supervision. The 'organically-minded' consultants were significantly less likely to want to supervise their own trainees in psychotherapy ( $P$ $=<.01)$. No significant difference was apparent between the two quartiles with regard to whether their junior doctors actually received supervision.

\section{Discussion}

A striking consensus was reached with regard to the need for juniors to receive supervision. More remarkable was the fact that a consensus existed about the mode of supervision. Consultant psychiatrists wished for their juniors to receive three hours of individual supervision a week. They wished this supervision to begin in the first or second year and wanted it to be obtained within their own hospital from a consultant psychiatrist with a special interest in psychotherapy. The organically-minded psychiatrists were more likely to favour supervision by a general psychiatrist who had special interest in psychotherapy but were less likely to supervise their own trainees, whereas psychotherapeutically-minded consultants very much favoured supervision by psychiatrists with a special interest rather than by psychoanalysts. These results raise the important question of whether supervision for general trainees should be given by a specialist psychotherapist trained in one particular brand of 
psychotherapy or by general psychiatrists with a special interest in psychotherapy and based within each NHS hospital. If the latter were a requirement the resources of a special interest consultant for three hours per week for each doctor would be needed wholly for psychotherapy supervision. The Royal College of Psychiatrists (1971) has preferred that the training of juniors be done by specialist psychotherapists, yet the consultants in our survey favoured training by general psychiatrists with a special interest in psychotherapy, and were opposed to their juniors being supervised solely by a psychoanalyst.

Both at Maudsley and St George's Hospitals, where independent psychotherapy departments have been set up. there tends to be friction between the full-time specialist psychotherapist and the general psychiatrist, leading to infighting and jealousy. Some general psychiatric attitudes can be paraphrased as follows: 'If only psychotherapists can train our junior doctors then perhaps only psychotherapists can do psychotherapy which, therefore, absolves us of the responsibility of both training the junior doctor and of doing any type of psychological or psychotherapeutic treatment ourselves.' On the other hand, the specialist psychotherapist could be paraphrased as saying, 'I am the only one who is skilled enough both to supervise juniors in psychotherapy and to do psychotherapy of a proper kind.'

It would be interesting to hear the opinions of other general psychiatrists about the way in which supervision of the various psychotherapies should be conducted within their hospital and in other teaching centres.

\section{BiBLIOGRAPHY}

Caine, T. M. \& Small, D. J. (1969) The Treatment of Mental IIIness: Science, Faith and the Therapeutic Personality. London University Press.

HAFNer, R. J., Leberman, S. \& Crisp, A. H. (1977) A survey of consultant psychiatrists' attitudes to their work, with particular reference to psychotherapy. British Journal of Psychiatry, 131, 415-19.

Hook, R. H. (1973) Psychotherapy: Practice and trainingopinions of members of the Australian and New Zealand College of Psychiatrists. Australian and New Zealand Journal of Psychiatry, 7, 87-96.

Leberman, S., Hafner, R. J. \& CrisP, A. H. (1978) Teaching psychotherapy in mental hospitals. British Journal of Psychiatry, 132, 398-402.

Pallis, D. J. \& Stoffelmeyer, B. E. (1973) Social attitudes and treatment orientation among psychiatrists. British Journal of Medical Psychology, 46, 75-81.

Royal College of Psychiatrists (1971) Guidelines for the train ing of general psychiatrists in psychotherapy. British Journal of Psychiatry, 119, 555-7.

SCHLESSINGer, N. (1966) Supervision of psychotherapy: A critical review of the literature. Archives of General Psychiatry, 15, 129-34.

\section{News Items}

\section{The Australian Journal of Psychotherapy}

The Australian Journal of Psychotherapy, published by the Psychotherapy Association of Australia, was launched last year. It will be published at least annually. Among other topics, the first issue contains discussions on the formative function of the human group; the psychotherapeutic process with children, adolescents and individuals in extreme situations; the dynamics of countertransference; and the intersection between linguistics and psychoanalysis. Manuscripts, book reviews and comments should be sent to Mrs V. McLaine, and subscription enquiries should be sent to Silvia Rodriguez, both at the following address: Department of Psychiatry and Behavioural Science, Royal Children's Hospital, Fleminton Road, Parkville, Victoria 3052.

\section{Peter Beckett Postgraduate Research Award}

The Peter Beckett Postgraduate Research Award, worth approximately $£ 275$, will be given to the candidate who, in the opinion of the Award Committee, has carried out the best research project in psychiatry during his or her postgraduate training. This research should normally have been carried out in Ireland. The Award is open to all postgraduate trainees in psychiatry who have completed at least three years of a formal training programme approved by the Committee. Applications should reach the Medical School Office by 31 December 1983 and should include a description of the completed research project. Address: Medical School Office, Faculty of Medical and Dental Sciences, Trinity College, Dublin 2.

\section{Journal of Reproductive and Infant Psychology}

The first part of this new journal was launched last month. There are three joint editors: Professor John Newton (Department of Obstetrics and Gynaecology, University of Birmingham); Dr Peter Stratton (Department of Psychology, University of Leeds); and Dr Mary Houston (Maternity Unit, John Radcliffe Hospital, Oxford). The executive editor is Christopher Macy (Department of Psychology, South Lincolnshire Health Authority). Manuscripts on psychological aspects of all matters relating to reproduction, both human and animal, should be sent to Christopher Macy, Department of Psychology, Orchard House, South Rauceby, Sleaford, Lincs. 